\title{
A trade-off between plant and soil carbon storage under elevated $\mathrm{CO}_{\mathbf{2}}$
}

C. Terrer ${ }^{1,2^{*}}$, R.P. Phillips ${ }^{3}$, B.A. Hungate ${ }^{4,5}$, J. Rosende ${ }^{6}$, J. Pett-Ridge ${ }^{1}$, M. Craig ${ }^{3,7}$, K.J. van Groenigen $^{8}$, T.F. Keenan ${ }^{9,10}$, B.N. Sulman ${ }^{7}$, B.D. Stocker ${ }^{11,12}$, P.B. Reich ${ }^{13,14}$, A.F.A. Pellegrini $^{2,15}$, E. Pendall ${ }^{14}$, H. Zhang ${ }^{16}$, R.D. Evans ${ }^{17}$, Y. Carrillo ${ }^{14}$, J. B. Fisher ${ }^{18,19}$, K. Van Sundert $^{20}$, Sara Vicca ${ }^{20}$, R.B. Jackson ${ }^{2}$.

\section{Affiliations}

${ }^{1}$ Physical and Life Sciences Directorate, Lawrence Livermore National Laboratory, Livermore, CA, 94550 USA.

${ }^{2}$ Department of Earth System Science, Stanford University, Stanford, CA, USA.

${ }^{3}$ Department of Biology, Indiana University, Bloomington, IN, 47405, USA.

${ }^{4}$ Center for Ecosystem Science and Society, Northern Arizona University, Flagstaff, Arizona 86011, USA.

${ }^{5}$ Department of Biological Sciences, Northern Arizona University, Flagstaff, AZ, USA.

${ }^{6}$ Institut de Ciència i Tecnologia Ambientals, Universitat Autònoma de Barcelona, Barcelona, Spain.

${ }^{7}$ Environmental Sciences Division and Climate Change Science Institute, Oak Ridge National Laboratory, Oak Ridge, TN, USA.

${ }^{8}$ Department of Geography, College of Life and Environmental Sciences, University of Exeter, Exeter, EX4 4 RJ, UK.

${ }^{9}$ Department of Environmental Science, Policy and Management, UC Berkeley, Berkeley, CA, USA.

${ }^{10}$ Climate and Ecosystem Sciences Division, Lawrence Berkeley National Laboratory, Berkeley, CA, USA.

${ }^{11}$ Department of Environmental Systems Science, ETH, Universitätsstrasse 2, 8092 Zürich, Switzerland

${ }^{12}$ Swiss Federal Institute for Forest, Snow and Landscape Research WSL, Birmensdorf, Switzerland

${ }^{13}$ Department of Forest Resources, University of Minnesota, St. Paul, MN, USA.

${ }^{14}$ Hawkesbury Institute for the Environment, Western Sydney University, Penrith 2571 Australia.

${ }^{15}$ Department of Plant Sciences, University of Cambridge, Cambridge, United Kingdom

${ }^{16}$ Environmental Change Institute, School of Geography and the Environment, University of Oxford, OX1 3QY, UK

${ }^{17}$ School of Biological Sciences and the Stable Isotope Core Laboratory, Washington State University, Pullman, WA 99164-4236, USA.

${ }^{18}$ Jet Propulsion Laboratory, California Institute of Technology, 4800 Oak Grove Dr., Pasadena, CA, 91109, USA

${ }^{19}$ Joint Institute for Regional Earth System Science and Engineering, University of California at Los Angeles, Los Angeles, CA, 90095, USA

${ }^{20}$ Plants and Ecosystems (PLECO), Biology Department, University of Antwerp, Wilrijk, Belgium

*Correspondence to: terrer@stanford.edu 
45 Abstract

46 Terrestrial ecosystems remove about $30 \%$ of the $\mathrm{CO}_{2}$ emitted by human activities each year ${ }^{1}$, yet

47 the persistence of this carbon sink partly depends on how plant biomass and soil carbon stocks

48 respond to future increases in atmospheric $\mathrm{CO}_{2}{ }^{2,3}$. While plant biomass often increases in

49 elevated $\mathrm{CO}_{2}\left(\mathrm{eCO}_{2}\right)$ experiments ${ }^{4-6}$, soil carbon has been observed to increase, remain

50 unchanged, or even decline ${ }^{7}$. The mechanisms driving this variation across experiments remain

51 poorly understood, creating uncertainty in climate projections ${ }^{8,9}$. Here, we synthesized data from

$52108 \mathrm{eCO}_{2}$ experiments and found that the effect of $\mathrm{eCO}_{2}$ on soil carbon stocks is best explained

53 by a negative relationship with plant biomass: when plant biomass is strongly stimulated by

$54 \mathrm{eCO}_{2}$, soil carbon accrual declines; conversely, when biomass is weakly stimulated, soil carbon

55 accumulates. This trade-off appears related to plant nutrient acquisition, whereby enhanced

56 biomass requires mining the soil for nutrients, which decreases soil carbon accrual. We found an

57 increase in soil carbon stocks with $\mathrm{eCO}_{2}$ in grasslands $(8 \pm 2 \%)$ and no increase in forests $(0 \pm 2 \%)$,

58 even though plant biomass in grassland responded less strongly $(9 \pm 3 \%)$ than in forest $(23 \pm 2 \%)$.

59 Ecosystem models do not reproduce this trade-off, which implies that projections of soil carbon

60 may need to be revised.

61

62 
64 The future of the land sink, especially of soil carbon, is particularly uncertain ${ }^{9}$. Soils can become either sources or sinks of carbon with rising levels of atmospheric $\mathrm{CO}_{2}$, depending on the prevalence of gains via photosynthesis or losses via respiration ${ }^{9,10}$. This uncertainty in terrestrial ecosystem model projections reflects uncertainty in both the mechanisms and the parameter values controlling soil carbon cycling under $\mathrm{eCO}_{2}{ }^{11}$.

Plant growth generally increases in response to $\mathrm{eCO}_{2}{ }^{4,12}$, with soil nutrients identified as the dominant factor explaining variability across experiments ${ }^{12-15}$. The effect of $\mathrm{eCO}_{2}$ on soil carbon stocks $\left(\beta_{\text {soil }}\right)$ is more equivocal. Although the expectation is that soil carbon will accrue as $\mathrm{eCO}_{2}$ increases plant growth ${ }^{16}$, a few experiments show increases in $\beta_{\text {soil }}$, many show no change, and some even show losses ${ }^{7}$. The observed variation in $\beta_{\text {soil }}$ across experiments is puzzling, and there is large disagreement regarding the dominant mechanisms explaining this variation ${ }^{7,17,18}$.

76

77

78

A positive relationship between the effects of $\mathrm{eCO}_{2}$ on plant biomass and soil carbon pools is expected if increased plant production under $\mathrm{eCO}_{2}$ increases carbon inputs (litter) into the soil. Indeed, a positive relationship between inputs and soil carbon storage is formalized in first order kinetics ${ }^{16}$ and is applied in most terrestrial ecosystem models ${ }^{19,20}$. Because the effect of $\mathrm{eCO}_{2}$ on plant aboveground biomass $\left(\beta_{\text {plant }}\right)$ is strongly correlated with the effect of $\mathrm{eCO}_{2}$ on litter production (Extended Data Fig. 1a, $r=0.81$ ) and on root production ${ }^{21}$, a positive relationship between $\beta_{\text {plant }}$ and $\beta_{\text {soil }}$ can thus be expected based on first order kinetics. This hypothesis, however, ignores soil carbon losses associated with accelerated soil organic matter decomposition sometimes observed under $\mathrm{eCO}_{2}{ }^{7,18}$. Plants acquire limiting resources from soils through carbon investment belowground in root growth, exudates, and symbiotic bacteria and fungi. Accelerated decomposition of soil organic matter fueled by plant carbon inputs can enable plant nutrient uptake (the "priming effect" ${ }^{, 2}$ ). The return on this belowground carbon investment is an increase in aboveground biomass production ${ }^{15}$. However, the priming effect can decrease soil carbon ${ }^{5}$. A negative relationship between $\beta_{\text {plant }}$ and $\beta_{\text {soil }}$ may thus emerge through the economics of plant resource acquisition.

Here, we evaluate the mechanisms of $\beta_{\text {soil }}$, including its relationship with $\beta_{\text {plant }}$, by synthesizing 268 observations of $\beta_{\text {soil }}$ from 108 eCO 2 experiments spanning the globe with coupled $\beta_{\text {plant }}-\beta_{\text {soil }}$ data (Supplementary Table 1) using meta-analysis techniques. We explore how well these mechanisms are represented in ecosystem models, and upscale the geographical distribution of $\beta_{\text {soil }}$ derived from experiments to identify regions where models might be missing important processes.

\section{Results}

Predictors of $\mathrm{SOC}$ accrual under $\mathrm{eCO}_{2}$

Overall, $\mathrm{eCO}_{2}$ increased soil carbon stocks by $4.6 \%$ across experiments (Fig. 1, 95\%-CI: $1.7 \%$ to $7.5 \%$ ). Given the strong variation in $\beta_{\text {soil }}$ across factors (Fig. 1), we used a random-forest approach in the context of meta-analysis (meta-forest) to quantify the importance of 19 potential predictors (Extended Data Table 1), including climate, soil, plant, and ecosystem variables and their interactions, accounting for covariation across predictors and potential nonlinearities. 
We found that $\beta_{\text {plant }}$ is the most important predictor of $\beta_{\text {soil }}$ (Extended Data Fig. 2a,b, $n=108$ ),

109 revealing a strong coupling between $\mathrm{CO}_{2}$-driven changes in plant biomass and soil carbon. In 110 addition, $\beta_{\text {soil }}$ increased with background SOC stocks (Fig. 1), also identified as an important 111 predictor.

112

113

114

115

116

117

118

119

120

121

122

123

124

125

126

127

128

129

130

131

132

133

134

135

136

137

138

139

140

141

142

143

144

145

146

147

148

149

150

151

152

153
Contrary to expectations from some first order models ${ }^{19,20}$, the relationship between $\beta_{\text {soil }}$ and $\beta_{\text {plant }}$ was negative. For the subset ( $n=73$ ) of field experiments with intact soils (non-potted plants and non-reconstructed soils), we found a significant interaction between $\beta_{\text {plant }}$ and nitrogen $(\mathrm{N})$ fertilization (Extended Data Fig. 2c, $p<0.01$ ). In non-fertilized experiments, the slope between $\beta_{\text {soil }}$ and $\beta_{\text {plant }}$ was significantly negative (Fig. $2 a, p<0.0001, R^{2}=0.67, n=38$ ), whereas in fertilized experiments the slope was less pronounced and nonsignificant $(\mathrm{p}=0.34, \mathrm{n}=35)$ (Extended Data Fig. 3a). In non-fertilized experiments, increases in plant biomass were associated with decreasing soil carbon stocks (Fig. 2a), consistent with the priming effect. In N-fertilized experiments, $\mathrm{eCO}_{2}$ generally increased both plant biomass and soil carbon (Extended Data Fig. $3 \mathrm{~b})$, in line with first order kinetics.

We propose a framework to explain the negative relationship between $\beta_{\text {soil }}$ and $\beta_{\text {plant }}$ based on plant nutrient acquisition strategies. Symbiotic associations between plants and arbuscular (AM) and ecto (ECM) mycorrhizal fungi mediate $\beta_{\text {plant }}$ (Extended Data Fig. 2d), resulting in much higher $\beta_{\text {plant }}$ in ECM than AM when nutrient availability is low (Fig. 2b). ECM plants efficiently increase $\mathrm{N}$-uptake under $\mathrm{eCO}_{2}$ (Fig. $2 \mathrm{c}, \mathrm{n}=12$ ), enhancing $\beta_{\text {plant. }}$ However, acquiring $\mathrm{N}$ from soil organic matter via priming accelerates soil carbon losses ${ }^{7}$, reducing $\beta_{\text {soil }}$ in ECM (Fig. $2 b$ ). In contrast, $\mathrm{eCO}_{2}$ did not significantly affect $\mathrm{N}$-uptake in AM systems (Fig. $2 \mathrm{c}, \mathrm{n}=12$ ). This outcome limits $\beta_{\text {plant }}$ in AM systems but stimulates $\beta_{\text {soil }}$ (Fig. 2b), likely due to increased carbon inputs through fine-root production and rhizodeposition ${ }^{21,23,24}$ combined with decreased carbon $\operatorname{losses}^{25}$. The composition of the soil organic matter may mediate this effect as well; AM plants produce more easily decomposable litter ${ }^{26}$, which enhances mineral-associated soil organic matter (MAOM) formation 27 and results in a greater fraction of soil carbon in MAOM under AM relative to ECM systems ${ }^{28,29}$. Indeed, $\mathrm{eCO}_{2}$ increases MAOM more strongly in AM systems than in ECM systems (Fig, 2d, $n=19$ ). Because MAOM is less accessible to microbial decomposers ${ }^{30}$, greater MAOM in AM systems could limit priming-induced losses and promote long-term soil carbon storage.

We considered three alternative mechanisms that could potentially explain this tradeoff. First, grasses allocate more carbon to roots than trees, which is associated with greater SOC stocks ${ }^{31,32}$. Because grassland species associate with AM fungi and the majority of tree species in the dataset associate with ECM, the observed increase in $\beta_{\text {soil }}$ in AM could be driven by ecosystem type rather than mycorrhizal type. However, we found that $\mathrm{eCO}_{2}$ effects on root biomass and fine-root production were generally lower in grasses than trees, and also in AM than ECM trees (Extended Data Fig. 4). Second, in non-fertilized experiments with available data $(\mathrm{n}=16), \mathrm{eCO}_{2}$ increased litter C:N by $8 \%$, which could reduce the decomposability of litter and the stabilization of carbon in the soil ${ }^{27}$. If litter quality is reduced more in ECM than AM, this could help explain why $\mathrm{eCO}_{2}$ increased SOC in AM, but not in ECM. However, the effect of $\mathrm{eCO}_{2}$ on litter quality was similar between mycorrhizal types (Extended Data Fig. 4). Finally, contrasting $\beta_{\text {soil }}$ in AM vs. ECM could be driven by larger background SOC in grasslands vs. forests, given that higher SOC is associated with higher $\beta_{\text {soil }}$ (Fig. 1). We found, however, that background SOC was similar 
between mycorrhizal types and ecosystem types (Extended Data Fig. 4). Thus, differences in root allocation, litter quality and background SOC in grasses vs. trees cannot explain the tradeoff between $\beta_{\text {soil }}$ and $\beta_{\text {plant }}$. Instead, losses in SOC associated with plant nutrient uptake (priming effect) in ECM, and gains associated with rhizodeposition in AM, are likely key. Experiments including both AM and ECM tree species should be targeted to better understand the impacts of nutrient-acquisition strategies under $\mathrm{eCO}_{2}$.

\section{Upscaling}

To explore the potential geographical distribution of $\beta_{\text {soil, }}$ we simulated a global FACE experiment (Fig. 3a). Unlike Fig. 1 where predictors are analyzed individually, our meta-forest model can upscale $\beta_{\text {soil }}$ from experiments while accounting for all important predictors simultaneously on a grid (Extended Data Figs. 5-6, 10-fold cross-validated $\mathrm{R}^{2}=0.51$ ). Grasslands, croplands, and shrublands showed a stronger potential to accumulate soil carbon in response to experimental e $\mathrm{CO}_{2}$ than forests (Fig. 3a,b). Soils in semi-arid herbaceous ecosystems were particularly responsive to $\mathrm{eCO}_{2}$, consistent with the results from the Mojave desert FACE experiment that showed $\mathrm{eCO}_{2}$-driven increases in soil carbon, but not biomass ${ }^{33}$. We identified large areas not currently sampled with $\mathrm{eCO}_{2}$ experiments, particularly in the tropics and high latitudes (Fig. 3c,d, Extended Data Fig. 6), where new experiments would help reduce uncertainties.

\section{Data-model comparison}

In addition to the negative relationship between $\beta_{\text {soil }}$ and $\beta_{\text {plant }}$, we also found a significantly negative relationship between $\beta_{\text {soil }}$ and the effect of $\mathrm{eCO}_{2}$ on aboveground biomass production (Extended Data Fig. 1b, $\mathrm{R}^{2}=0.55, p<0.001$ ), which is strongly correlated with litter production (Extended Data Fig. 1a, $\mathrm{R}^{2}=0.63, r=0.81, p<0.01$ ). This result questions the positive relationship between litter inputs and soil carbon stocks encoded in most ecosystem models. Thus, we investigated the relationship between $\beta_{\text {soil }}$ and $\beta_{\text {plant }}$ in models from three different model ensembles (description in Extended Data Table 2). First, models from the FACE model-data synthesis project (FACE-MDS) ${ }^{34}$ mimic the experimental treatment in six $\mathrm{eCO}_{2}$ experiments and allow for a direct comparison with respective observations. While observations from the six experiments included in FACE-MDS showed a negative relationship between $\beta_{\text {soil }}$ and $\beta_{\text {plant }}$ (Fig. 4a, blue line, $\mathrm{R}^{2}=0.99, \mathrm{p}<0.001$ ), the twelve models simulated a positive relationship when pooled by experiment (Fig. $4 \mathrm{a}$, red line, $\mathrm{R}^{2}=0.91, \mathrm{p}<0.01$ ). The relationship across all models individually was positive as well (Extended Data Fig. $7 \mathrm{a}$, dashed line, $\mathrm{R}^{2}=0.37, \mathrm{p}<0.0001$ ), and none of the individual models was able to reproduce the observations. Second, to investigate whether the same relationships emerge across the globe and in simulations where $\mathrm{CO}_{2}$ increases gradually, we evaluated global century-scale relationships between $\beta_{\text {soil }}$ and $\beta_{\text {plant }}$ from the TRENDY and CMIP5 model ensembles (Fig. 4b,c). Overall, TRENDY and CMIP5 models did not simulate a negative relationship either (Fig. $4 \mathrm{~b}, \mathrm{c}$ ). Instead, most models simulated a positive relationship and the vast majority of model simulations fell into the upper-right quadrant (Extended Data Fig. 7b,c), reflecting that inputs drive SOC accumulation in the first-order decomposition soil model structure common to the models.

In TRENDY and CMIP5 model simulations, $\beta_{\text {soil }}$ was estimated over a much longer time period than in experiments (Extended Data Table 2). Given the relatively slow turnover times of SOC pools, and the slow pace of changes in species composition and evolutionary pressures on both 
plants and soil microbes, long-term effects likely differ to those found in experiments. However, first order models simulate a positive relationship $\beta_{\text {plant }}: \beta_{\text {soil }}$ when they are forced to simulate the temporal scale of experiments (Fig. 4a), suggesting important processes are missing in models. By including explicit links between plant growth, belowground carbon allocation and SOC decomposition rates, models may more effectively reproduce the observed negative relationship between $\beta_{\text {soil }}$ and $\beta_{\text {plant }}$ and improve long-term projections.

To estimate the error in terrestrial ecosystem model projections of $\beta_{\text {soil }}$ caused by ignoring the tradeoff between $\beta_{\text {soil }}$ and $\beta_{\text {plant }}$, we calculated "expected"- $\beta_{\text {soil }}$ as a function of our upscaled $\beta_{\text {plant }}$ and the ratio $\beta_{\text {soil }} / \beta_{\text {plant }}$ simulated by CMIP5 models. CMIP5 models overestimated $\beta_{\text {soil }}$ for forests (Fig. 3e,f, red color). In contrast, CMIP5 models underestimated $\beta_{\text {soil }}$ in large areas dominated by grasses (Fig. 3e,f, blue color), likely because they do not account for the effects of rhizodeposition on $\beta_{\text {soil }}{ }^{21}$. Results with TRENDY models were similar (Extended Data Fig. 8).

\section{Discussion}

In summary, our synthesis of experiments shows that soil carbon stocks can increase by $\sim 5 \%$ in response to a $65 \%$ step increase in $\mathrm{CO}_{2}$ concentrations, with a strong coupling between $\mathrm{CO}_{2}$ driven changes in plant aboveground biomass and soil carbon. However, the coupling between plant biomass and soils is an inverse relationship (Fig. 2a, Extended Data Fig. 1b), opposite to that simulated by many ecosystem models (Fig. 4). The effect of $\mathrm{eCO}_{2}$ on soil carbon storage is dependent on a fine balance between changes in inputs and changes in turnover ${ }^{18}$, where the latter is dependent on root-microbe-mineral interactions in the rhizosphere. Our results suggest that rhizosphere responses, and especially priming, explain much of the variation in $\beta_{\text {soil }}$ across experiments (Fig. 2). Most models focus on carbon inputs and underestimate rhizosphere effects $^{11,20,35}$, likely explaining the disagreement in $\beta_{\text {soil }}$ between observations and models (Figs. $3,4)$. We propose a framework to explain $\beta_{\text {soil }}$ based on nutrient acquisition strategies ${ }^{15,36,37}$. On one end of the spectrum, substantial acquisition of soil $\mathrm{N}$ is possible via priming ${ }^{5}$ in ECM plants, causing a stronger plant biomass sink at the expense of soil carbon accrual. On the other end, low nutrient availability strongly constrains the plant biomass $\sin ^{38}$ in AM plants. However, the ecosystem-level sink is not necessarily eliminated; instead, $\mathrm{eCO}_{2}$ can trigger soil carbon accrual through plant carbon-allocation belowground ${ }^{21,23,24}$. When plant growth is severely limited by $\mathrm{N}$ or other nutrients, $\mathrm{eCO}_{2}$ may only cause a transient priming effect in $\mathrm{ECM}$, with high soil decomposition and insufficient nutrient uptake rendering no ecosystem-level sink ${ }^{39}$.

Our results underline the potential of grassland soils to store carbon as atmospheric $\mathrm{CO}_{2}$ levels continue to rise. The results also suggest that current state of the art models may overestimate the soil carbon sequestration potential of forests in large parts of the world. Previous studies suggest that the potential of vegetation to take up $\mathrm{CO}_{2}$ will slow later in this century due to nutrient constraints ${ }^{12-14,38,39}$. Our synthesis indicates that these nutrient constraints extend to carbon storage in ecosystems as a whole - through a partial tradeoff between increased plant growth and soil carbon storage whereby ecosystems where plant growth is more nutrient limited accumulate more carbon belowground. The apparent mismatch between observations and how most models represent the biomass-to-soil link suggests that many terrestrial ecosystem models do not adequately represent the critical processes driving soil carbon accumulation. Models are evolving to include more sophisticated representations of soil nutrient cycling, and some now include microbial activity explicitly ${ }^{36,40}$. This change towards coupled carbon-nutrient cycling 
mediated by plant-soil interactions is important for more realistically and accurately modeling the carbon cycle today and for projecting the land sink in the future.

\section{References (main)}

251 2. Schimel, D., Stephens, B. B. \& Fisher, J. B. Effect of increasing CO2 on the terrestrial carbon cycle. Proc.

3. Keenan, T. et al. Recent pause in the growth rate of atmospheric $\mathrm{CO} 2$ due to enhanced terrestrial carbon uptake. Nat. Commun. 7, 13428 (2016).

4. $\quad$ Baig, S., Medlyn, B. E., Mercado, L. M. \& Zaehle, S. Does the growth response of woody plants to elevated $\mathrm{CO} 2$ increase with temperature? A model-oriented meta-analysis. Glob. Change Biol. 21, $4303-4319$ (2015).

5. Drake, J. E. et al. Increases in the flux of carbon belowground stimulate nitrogen uptake and sustain the long term enhancement of forest productivity under elevated CO2. Ecol. Lett. 14, 349-357 (2011).

6. Norby, R. J. et al. Forest response to elevated $\mathrm{CO} 2$ is conserved across a broad range of productivity. Proc. Natl. Acad. Sci. 102, 18052-18056 (2005).

7. van Groenigen, K. J., Qi, X., Osenberg, C. W., Luo, Y. \& Hungate, B. A. Faster Decomposition Under Increased Atmospheric CO2 Limits Soil Carbon Storage. Science 344, 508 (2014).

8. Friedlingstein, P. et al. Uncertainties in CMIP5 Climate Projections due to Carbon Cycle Feedbacks. J. Clim. 27, 511-526 (2014).

9. Todd-Brown, K. E. O. et al. Changes in soil organic carbon storage predicted by Earth system models during the 21st century. Biogeosciences 11, 2341-2356 (2014).

10. Heimann, M. \& Reichstein, M. Terrestrial ecosystem carbon dynamics and climate feedbacks. Nature 451, 289-292 (2008).

11. Bradford, M. A. et al. Managing uncertainty in soil carbon feedbacks to climate change. Nat. Clim. Change 6, 751-758 (2016).

12. Terrer, C. et al. Nitrogen and phosphorus constrain the CO 2 fertilization of global plant biomass. Nat. Clim. Change 9, 684-689 (2019).

13. Reich, P. B., Hungate, B. A. \& Luo, Y. Carbon-Nitrogen Interactions in Terrestrial Ecosystems in Response to Rising Atmospheric Carbon Dioxide. Annu. Rev. Ecol. Evol. Syst. 37, 611-636 (2006).

14. Norby, R. J. \& Zak, D. R. Ecological lessons from free-air CO2 enrichment (FACE) experiments. Annu. Rev. Ecol. 42, 181-203 (2011).

15. Terrer, C. et al. Ecosystem responses to elevated $\mathrm{CO} 2$ governed by plant-soil interactions and the cost of nitrogen acquisition. New Phytol. 217, 507-522 (2018).

16. Olson, J. S. Energy Storage and the Balance of Producers and Decomposers in Ecological Systems. Ecology 44, 322-331 (1963).

17. Hungate, B. A. et al. Assessing the effect of elevated carbon dioxide on soil carbon: a comparison of four meta analyses. Glob. Change Biol. 15, 2020-2034 (2009).

18. Kuzyakov, Y., Horwath, W. R., Dorodnikov, M. \& Blagodatskaya, E. Review and synthesis of the effects of elevated atmospheric $\mathrm{CO} 2$ on soil processes: No changes in pools, but increased fluxes and accelerated cycles. Soil Biol. Biochem. 128, 66-78 (2019).

19. Tian, H. et al. Global patterns and controls of soil organic carbon dynamics as simulated by multiple terrestrial biosphere models: Current status and future directions. Glob. Biogeochem. Cycles 29, 775-792 (2015).

20. Todd-Brown, K. E. O. et al. Causes of variation in soil carbon simulations from CMIP5 Earth system models and comparison with observations. Biogeosciences 10, 1717-1736 (2013).

21. Nie, M., Lu, M., Bell, J., Raut, S. \& Pendall, E. Altered root traits due to elevated CO2: a meta analysis. Glob. Ecol. Biogeogr. 22, 1095-1105 (2013).

22. Kuzyakov, Y. Priming effects: Interactions between living and dead organic matter. Soil Biol. Biochem. 42, 1363-1371 (2010).

23. Treseder, K. K. A meta analysis of mycorrhizal responses to nitrogen, phosphorus, and atmospheric $\mathrm{CO} 2$ in field studies. New Phytol. 164, 347-355 (2004).

24. Jastrow, J. D. et al. Elevated atmospheric carbon dioxide increases soil carbon. Glob. Change Biol. 11, 20572064 (2005).

25. Carrillo, Y., Dijkstra, F. A., LeCain, D. \& Pendall, E. Mediation of soil C decomposition by arbuscular mycorrizhal fungi in grass rhizospheres under elevated CO2. Biogeochemistry 127, 45-55 (2016). 
26. Averill, C., Bhatnagar, J. M., Dietze, M. C., Pearse, W. D. \& Kivlin, S. N. Global imprint of mycorrhizal fungi on whole-plant nutrient economics. Proc. Natl. Acad. Sci. 116, 23163-23168 (2019).

27. Cotrufo, M. F., Wallenstein, M. D., Boot, C. M., Denef, K. \& Paul, E. The Microbial Efficiency-Matrix Stabilization (MEMS) framework integrates plant litter decomposition with soil organic matter stabilization: do labile plant inputs form stable soil organic matter? Glob. Change Biol. 19, 988-995 (2013).

28. Cotrufo, M. F., Ranalli, M. G., Haddix, M. L., Six, J. \& Lugato, E. Soil carbon storage informed by particulate and mineral-associated organic matter. Nat. Geosci. 12, 989-994 (2019).

29. Craig, M. E. et al. Tree mycorrhizal type predicts within-site variability in the storage and distribution of soil organic matter. Glob. Change Biol. 24, 3317-3330 (2018).

30. Schmidt, M. W. I. et al. Persistence of soil organic matter as an ecosystem property. Nature 478, 49-56 (2011).

31. Jobbágy, E. G. \& Jackson, R. B. The Vertical Distribution of Soil Organic Carbon and Its Relation to Climate and Vegetation. Ecol. Appl. 10, 423-436 (2000).

32. Sokol, N. W., Kuebbing, S. E., Karlsen Ayala, E. \& Bradford, M. A. Evidence for the primacy of living root inputs, not root or shoot litter, in forming soil organic carbon. New Phytol. 221, 233-246 (2019).

33. Evans, R. D. et al. Greater ecosystem carbon in the Mojave Desert after ten years exposure to elevated $\mathrm{CO}_{2}$. Nat. Clim. Change 4, 394-397 (2014).

34. Walker, A. P. et al. FACE-MDS Phase 2: Model Output. https://www.osti.gov/dataexplorer/biblio/dataset/1480327 (2018) doi:10.15485/1480327.

35. Wieder, W. R. et al. Carbon cycle confidence and uncertainty: Exploring variation among soil biogeochemical models. Glob. Change Biol. 24, 1563-1579 (2018).

36. Sulman, B. N. et al. Diverse Mycorrhizal Associations Enhance Terrestrial C Storage in a Global Model. Glob. Biogeochem. Cycles 33, 501-523 (2019).

37. Shi, M., Fisher, J. B., Brzostek, E. R. \& Phillips, R. P. Carbon cost of plant nitrogen acquisition: global carbon cycle impact from an improved plant nitrogen cycle in the Community Land Model. Glob. Change Biol. 22, 1299-1314 (2016).

38. Norby, R. J., Warren, J. M., Iversen, C. M., Medlyn, B. E. \& McMurtrie, R. E. CO2 enhancement of forest productivity constrained by limited nitrogen availability. Proc. Natl. Acad. Sci. 107, 19368-19373 (2010).

39. Jiang, M. et al. The fate of carbon in a mature forest under carbon dioxide enrichment. Nature 580, 227-231 (2020).

40. Wieder, W. R., Bonan, G. B. \& Allison, S. D. Global soil carbon projections are improved by modelling microbial processes. Nat. Clim. Change 3, 909-912 (2013). 
Fig. 1. Meta-analysis of the effect of elevated $\mathrm{CO}_{2}$ on soil carbon (\%) across different factors. $\mathrm{n}=108$. Overall means and $95 \%$ confidence intervals are given; we interpret $\mathrm{CO}_{2}$ effects when the zero line is not crossed by the confidence intervals. Arrows represent $95 \%$ confidence intervals that extend beyond the limits of the plot. Soil carbon stocks represent values in ambient $\mathrm{CO}_{2}$ plots as a continuous variable, here expressed as intervals of equal sample size for illustration purposes. Values in parenthesis are sample sizes.

$\mathrm{CO}_{2}$ effects represent, on average, an increase in $\mathrm{CO}_{2}$ from $372 \mathrm{ppm}$ to 616 ppm. FACE: Free Air $\mathrm{CO}_{2}$ Enrichment, OTC: Open Top Chamber, AM: arbuscular mycorrhizal, AM-ER: mix of AM and ericoid mycorrhizal, ECM: ectomycorrhizal, N-fixer: fixation of atmospheric nitrogen.

Fig. 2. Elevated $\mathrm{CO}_{2}$ experiments show an inverse relationship between the effects of elevated $\mathrm{CO}_{2}$ on plant biomass and soil carbon (a). This inverse relationship can be explained by the different efficiencies in plant nutrient uptake (c) between arbuscular mycorrhizal (AM) and ectomycorrhizal (ECM) nutrient-acquisition strategies driving opposite effects on plant biomass and soil carbon pools (b), including mineral-associated soil organic matter (MAOM) stocks (d). Regression line (a) is based on a quadratic mixed-effects meta-regression model and $95 \%$ confidence interval $\left(R^{2}=0.67, p<0.0001, n=38\right)$. Dots in (a) represent the individual experiments in the meta-analysis, with dot sizes proportional to model weights. Dots in (b-d) represent overall effect sizes from a meta-analysis and 95\% confidence intervals. Data shown here are for non-fertilized experiments (see Extended Data Fig. 3 for nutrient-fertilized experiments).

Fig. 3. Effect of elevated $\mathrm{CO}_{2}(\sim 240 \mathrm{ppm})$ on soil carbon stocks upscaled from $108 \mathrm{CO}_{2}$ experiments. $(\mathrm{a}, \mathrm{b})$ Relative effect of elevated $\mathrm{CO}_{2}$ on soil carbon upscaled based on a meta-forest approach with data from $\mathrm{CO}_{2}$ experiments. (c, d) Standard error in (a). Green dots represent the location of the $\mathrm{CO}_{2}$ experiments included in the analysis. (e,f) Difference between expected $\mathrm{CO}_{2}$ effects on soil carbon stocks based on CMIP5 models and upscaled based on experiments (shown in a). Expected values result from the relationship between $\beta_{\text {soil }}$ and $\beta_{\text {plant }}$ coded in models. Positive values (red color) indicate an overestimation by models; negative values (blue color) indicate an underestimation by models. Shaded areas between -15 to 15 and from 60 to 90 degrees in latitude represent ecosystems not well sampled by experiments and are excluded from the analysis. Boxplots show the median, the first to third quartile, the $1.5 \mathrm{x}$ interquartile ranges, and outliers.

Figure 4. Comparison of modeled and measured relationships between aboveground biomass and soil carbon responses to $\mathrm{CO}_{2}$. (a) Relationship observed (blue) and modeled (red) across $6 \mathrm{eCO}_{2}$ experiments. Model results are based on 12 models applied to the same 6 experiments with a common forcing and initialization protocol. Experiments included are Duke FACE (DUKE), Kennedy Space Center (KSCO), Nevada Desert FACE (NDFF), Oak Ridge FACE (ORNL), Prairie PHACE (PHAC), and Rhinelander (RHIN). Regression line across observations in (a) is based on a quadratic meta-regression model. Modeled simulations averaged in (a) for each experiment are from the FACE Model-DataSynthesis project phase 2. (b,c) Global-scale relationship simulated by ecosystem models (b) from the TRENDY ensemble for the historical increase in $\mathrm{CO}_{2}$ since the year 1700 and (c) from the CMIP5 ensemble for an increase in $\mathrm{CO}_{2}$ from $372 \mathrm{ppm}$ to $616 \mathrm{ppm}$ as in $\mathrm{eCO}_{2}$ experiments. Dotted lines are the $1: 1$ line. 


\section{Methods}

385 Overview. Here, we collect data on the effects of elevated $\mathrm{CO}_{2}$ on soil carbon stocks $\left(\beta_{\text {soil }}\right)$ in both relative and absolute terms and synthesize them through meta-analysis. We also collect data on climatic, experimental, and vegetation characteristics that could potentially explain variability in $\beta_{\text {soil }}$ ("predictors"). In Fig. 1, we show a descriptive meta-analysis of overall $\beta_{\text {soil }}$ across different predictor factors. We next combine the strengths of meta-analysis (e.g. accounting for within-study variability, weights) with random-forest (e.g. computational efficiency, nonlinearities, interactions) - meta-forest - to quantify the relative importance of 19 predictors in explaining variation in $\beta_{\text {soil }}$ in the dataset. In Fig. 2 , we describe the regression between $\beta_{\text {soil }}$ and its most important predictor $\left(\beta_{\text {plant }}\right)$, and explore the possible mechanisms underlying this relationship. In Fig. 3, we apply the data-trained meta-forest model to upscale $\beta_{\text {soil. }}$. Finally, we investigate whether the emerging relationship between $\beta_{\text {soil }}$ and $\beta_{\text {plant }}$ found in experiments is represented in models (Fig. 4).

Data collection. We have compiled the openly available Report of Mutualistic Associations, Nutrients, and Carbon under $\mathrm{eCO}_{2}$ (ROMANCE) v1.0 dataset ${ }^{41}$ with data on soil organic carbon (SOC) and plant biomass from $\mathrm{eCO}_{2}$ experiments. Expanding van Groenigen et al's 2014 metaanalysis $^{7}$ of 53 experiments reporting soil organic carbon (SOC) data, we used Google Scholar to gather a total of 166 studies related to $\mathrm{eCO}_{2}$ experiments, published from 1st January 2013-1st May 2019. Search terms were either "elevated $\mathrm{CO}_{2}$ ", "increased $\mathrm{CO}_{2}$ " or " $\mathrm{CO}_{2}$ enrichment" and either "soil carbon" or "plant biomass." To account for experiments that could have been omitted by van Groenigen et al. prior to 2013, we consulted the list of $\mathrm{CO}_{2}$ experiments from INTERFACE (https:/www.bio.purdue.edu/ INTERFACE/experiments.php), the Global List of FACE Experiments from the Oak Ridge National Laboratory (http://facedata.ornl.gov/global_face.html), the ClimMani database on manipulation experiments (www.climmani.org) and the database described by Dieleman et al. ${ }^{42}$. We recorded the structure of each $\mathrm{eCO}_{2}$ experiment from the papers, taking into consideration the start date and total duration of the experiment (years), and the location of the experiment (coordinates). When the data were presented in figures, mean values and standard error were extracted using GraphClick.

For this meta-analysis, only one datum per experiment was considered to avoid pseudoreplication. The effects of $\mathrm{eCO}_{2}$ on soil $\mathrm{C}$ pools are modulated by increases in soil $\mathrm{C}$ inputs from plant litter as well as feedbacks between plants and soils altering soil biogeochemical cycles that can take several years to occur. Thus, we used the most recent measurements in each experiment as the most representative data of the effect of $\mathrm{eCO}_{2}$ on $\mathrm{SOC}$.

For plant biomass, measurements across different time-points were combined so that only one effect size was analyzed per study. The combined effect size and variance that account for the correlation among the different time-point measurements was calculated following the method described in Borenstein et al. $^{43}$, using a conservative approach by assuming nonindependency of multiple outcomes $(r=1)$ and performed using the MAd package in $\mathrm{R}^{44}$. We collected data on both aboveground biomass stocks and production. When aboveground biomass production data were unavailable, we collected plant data in the following order or preference: NPP, aboveground biomass increment, foliage production and yield. When biomass or soil data were not reported, studies were excluded. We also included the data on litter production reported by Song and $\operatorname{Wan}^{45}$ to study the interactions with aboveground biomass and production data.

Soil carbon measurements in the dataset were reported at different depths, varying from 5 to $30 \mathrm{~cm}$ maximum depth, with an average depth of $\sim 20 \mathrm{~cm}$. When upscaling $\mathrm{eCO}_{2}$ effects on 
SOC through meta-forest, we included a fixed value of $0-30 \mathrm{~cm}$ in depth as a covariate to control for the influence of soil depth, interpolating predictions for the same soil depth of models.

SOC data reported as concentrations were transformed to stocks $\left(\mathrm{g} \mathrm{m}^{-2}\right)$ using soil bulk density. When bulk density was not reported, we used data reported for similar experiments within the same site or assumed a bulk density of $1 \mathrm{~g} \mathrm{~cm}^{-3}$. Assumptions are indicated in the dataset.

Studies from ROMANCE v1.0 were not included in the meta-analysis if they met any of the following exclusion criteria: i) studies with no SOC data; ii) papers with no plant biomass data; iii) studies where the duration of the $\mathrm{eCO}_{2}$ experiment lasted less than 0.5 years. A total of 138 independent experiments were collected, of which, 108 were included in the final analysis based on these exclusion criteria.

Meta-analysis. Two types of effect size were calculated:1) the log response ratio (mean response in elevated-to-ambient $\mathrm{CO}_{2}$ plots), to measure effect sizes in relative terms (\%) for each experiment; and 2) the raw mean difference, to compute effect sizes in absolute terms $\left(\mathrm{g} \mathrm{m}^{-2}\right)$. For each experiment, we collected data on SOC stocks, standard deviation and sample size under elevated and ambient (control) $\mathrm{CO}_{2}$ plots. Effect sizes were calculated using the escalc function from the R package metafor ${ }^{46}$. We calculated overall effects in a weighted, mixed-effects model using the rma.mv function in metafor. The potential non-independency of studies within the same site (e.g. different species, different treatments) was accounted for by including "site" as a random effect. Effect size measurements from individual studies in the meta-analysis were weighted by the inverse of the variance ${ }^{47} .13 \%$ of studies did not report standard deviations, which were thus imputed using Rubin and Schenker's ${ }^{48}$ resampling approach from studies with similar means. These calculations were performed using the R package metagear ${ }^{49}$.

Variable Importance and upscaling approach. 19 potential moderators were coded (Extended Data Table 1). Including all 19 moderators in a meta-regression risks overfitting the model. Therefore, we applied the R package 'metaforest ${ }^{50}$ to identify potentially relevant moderators in predicting $\beta_{\text {soil }}$ across the complete dataset of 108 studies. The approach is based on the machinelearning 'random forest' algorithm, which is robust to overfitting, and is integrated in a metaanalytic context by incorporating the variance and weight of each experiment as in classic metaanalysis (see above).

As an initial step, we conducted variable pre-selection by including the 19 predictors in metaforest with 10,000 iterations and replicated 100 times with a recursive algorithm in the preselect function from metafor ${ }^{46}$. Moderators that consistently displayed negative variable importance (i.e., that showed a reduction in predictive performance) were dropped using the preselect_vars function. Moderators that improved predictive performance were then carried forward to optimize the model. Parameters of the meta-forest model were optimized using the train function from the caret package ${ }^{51}$, and calculated 10 -fold cross validated $\mathrm{R}^{2}$ with $75 \%$ of the data used as training data and $25 \%$ for validation. Unlike maximum likelihood modelselection approaches, this method can handle many potential predictors and their interactions and considers non-linear relationships. Partial dependence plots were produced which visualize the association of each moderator with the effect size, while accounting for the average effect of all other moderators.

As a sensitivity test, and to identify important interactions between predictors, we ran an alternative model-selection procedure using maximum likelihood estimation. For this purpose, 
we used the rma.mv() function from the metafor R package ${ }^{46}$ and the glmulti() function from the glmulti R package ${ }^{52}$ to automate fitting of all possible models containing the 5 most important predictors and their interactions (level=2). Model selection was based on Akaike Information Criterion corrected for small samples (AICc), with the relative importance value for a particular predictor equal to the sum of the Akaike weights (probability that a model is the most plausible model) for the models in which the predictor appears.

Finally, the data-trained meta-forest model was applied to global gridded data of preselected predictors (see Extended Data Table 1 for gridded data sources) to estimate the effect of elevated $\mathrm{CO}_{2}$ on SOC. The resulting global maps are geographically constrained to ecosystems best represented by experiments. We remove the estimates for latitudes comprised between -15 to 15 degrees, corresponding to tropical ecosystems not sampled by experiments (Fig. 3c, green dots), and from 60 to 90 degrees.

Nitrogen fertilization and soil disturbance. We used the information reported in the papers to assess whether the soils were exposed to external inputs of N fertilization ("yes") or not ("no"). Experiments were also classified as either having "disturbed" or "intact" soils as noted in the papers. If not, experiments which used pots or reconstructed soils were categorized as disturbed. We used the same approach and classification as in $\mathrm{re}^{53}$.

To upscale the effect of nitrogen fertilization and disturbance on $\beta_{\text {soil }}$, we reclassified the ESA CCI land cover map https://www.esa-landcover-cci.org/?q=node/164. Reclassification files are accessible online https://figshare.com/account/projects/74721/articles/11710155. For example, we classify "Cropland, rainfed"-"Herbaceous cover" (class 11) and "Cropland, irrigated or post-flooding" (class 20) as fertilized.

Nutrient-acquisition strategy classification. We considered the importance of the type of symbiotic association as a driver of $\mathrm{eCO}_{2}$ effects on soil $\mathrm{C}$. Mycorrhizal status includes AM, ECM and a mix of AM and ericoid (ER) mycorrhizal fungal associations. Here, we also considered some plant species known to associate with $\mathrm{N}$-fixing microorganisms. We refer to this classification as "Symbiotic", because it includes both mycorrhizal status and N-fixation. Together, these four symbiosis types represent different mechanisms plants use to acquire nutrients ${ }^{15}$.

We assessed the impact of the dominant symbiotic association type by classifying all studies as ECM, AM, AM-ER, and N-fixers, using the check-lists by Wang et al. ${ }^{54}$ and Maherali et al. ${ }^{55}$, with additional classifications derived from the literature. Species that associate with both ECM and AM (e.g. Populus spp.) were classified as ECM because these species can potentially benefit from increased $\mathrm{N}$-availability due to the presence of ECM fungi ${ }^{56}$. Most of the $\mathrm{N}$-fixers in the dataset were associated with both $\mathrm{N}$-fixing symbionts as well as AM fungi, but we classified them as $\mathrm{N}$-fixers because these species can potentially benefit from $\mathrm{N}$ acquired through $\mathrm{N}$-fixation.

MAOM data. We retrieved data on mineral-associated organic matter (MAOM) and particulate organic matter (POM) for the subset of studies employing size or density fractionation of soil organic matter $(\mathrm{n}=19)$. Because of methodological differences, POM is loosely defined as organic matter recovered in the total coarse (typically $>53 \mu \mathrm{m}$ ) or light (typically $<1.6 \mathrm{~g} \mathrm{~cm}-3$ ) soil fraction. Where MAOM was not reported, it was estimated based on mass balance by subtracting the POM fraction from total C. 
FACE Model-Data-Synthesis. We use data from the FACE Model-Data Synthesis (FACEMDS) Project Phase $2^{57-62}$, in which 12 models were applied to $6 \mathrm{eCO}_{2}$ experiments. Each model covered the time periods representative of the FACE experiments, following a standardized protocol including meteorological forcing, $\mathrm{CO}_{2}$ concentration, site history, and vegetation characteristics for each site.

Experiments included in the FACE-MDS Phase 2 were Duke FACE ${ }^{63}$, Kennedy Space Center $^{64}$, Nevada Desert FACE ${ }^{65}$, Oak Ridge FACE ${ }^{38}$, Prairie PHACE ${ }^{66,67}$ and Rhinelander ${ }^{68}$. Models included were CLM4.0 ${ }^{69}$, CLM4.5, DAYCENT, CABLE, JULES ${ }^{70}$, LPJ-GUESS, OCN, TECO, ORCHIDEE ${ }^{71}$, GDAY, ISAM, and SDGVM. See ref. ${ }^{61}$ for an overview of model structures and processes. As in the observational data, we compared relative changes in aboveground biomass and soil carbon stocks of each experiment for $\mathrm{eCO}_{2}$ relative to control treatments.

TRENDY models We use model outputs from the TRENDY v7 S1 simulations, where each model is driven by standardized forcings of observed increasing $\mathrm{CO}_{2}$ for years $1700-2018 \mathrm{CE}$, and constant preindustrial climate and land use. We selected six models that provided outputs for aboveground vegetation carbon (taken as the sum of wood and leaf carbon), soil carbon, and NPP (CABLE-POP ${ }^{72}$, CLM $.0^{73}$, ISAM $^{74}$, LPJ-GUESS $^{75}$, ORCHIDEE $^{71}$, ORCHIDEE-CNP $^{76}$ ). Wood carbon often includes coarse roots in models. Here, we evaluate relative changes and numbers are not sensitive to the exact definition. Description of models can be found in ref ${ }^{77}$. Briefly, ORCHIDEE-CNP includes an interactive $\mathrm{N}$ and phosphorus cycle, whereas ORCHIDEE is a C-only model. The rest have coupled $\mathrm{C}$-N cycles. Relative changes were calculated based on means over ten initial years ( $i$, vary depending on the model) and $j=2008-2017$ as $\left(\mathrm{C}_{\mathrm{j}}-\mathrm{C}_{\mathrm{i}}\right) / \mathrm{C}_{\mathrm{i}}$. To reduce effects of discrepant response timescales of soil $\mathrm{C}$ and biomass, we estimated the steady-state soil $\mathrm{C}$ storage $\left(C^{*}\right)$ as:

$$
C^{*}=\frac{C_{j}}{1-\frac{\Delta C_{j}}{N P P_{j}}},
$$

where $\Delta C_{j}$ is the change in soil $\mathrm{C}$ over the years 2008-2017. The relative change in soil $\mathrm{C}$ is then taken as $\left(C^{*}-C_{i}\right) / C_{i}$. Data shown in Fig. 4 is based on pooled data from all six models. We randomly sampled outputs from $\mathrm{N}$ gridcells for each model in order not to bias the visualization towards models with a large number of gridcells (i.e. higher resolution). $\mathrm{N}$ is chosen as the number of gridcells in the model with the coarsest resolution.

CMIP5 Models - Expected $\boldsymbol{\beta}_{\text {soil }}$. We used projected SOC (Csoil) and biomass pool (Cveg) responses to rising $\mathrm{CO}_{2}$ as simulated by CMIP5 models as a comparison for the upscaled values we derive from experiments. Specifically, we used data from the experiment "esmFixClim1", in which $\mathrm{CO}_{2}$ is increased by $1 \%$ per year from $285 \mathrm{ppm}$. In the esmFixClim 1 experiment, the increase in $\left[\mathrm{CO}_{2}\right]$ only affects vegetation and not the radiation code of the models, enabling a quantification of the effect of $\mathrm{eCO}_{2}$ in isolation (e.g. excluding warming), and thus a close comparison with $\mathrm{eCO}_{2}$ experiments. At a $\left[\mathrm{CO}_{2}\right]$ increasing rate of $+1 \%$ year ${ }^{-1},\left[\mathrm{CO}_{2}\right]$ reaches 372 ppm (average concentration in ambient $\mathrm{CO}_{2}$ plots in the dataset) in the 28th year and $616 \mathrm{ppm}$ (average concentration in elevated $\mathrm{CO}_{2}$ plots in the dataset) in the 78 th year. $\Delta$ Cveg and $\Delta$ Csoil were calculated as the difference between the respective carbon stocks in the 28th and the 78th year. 
Though plants in both experiments and our CMIP5 dataset see a similar increase in $\left[\mathrm{CO}_{2}\right]$, experiments simulate a step increase in $\mathrm{CO}_{2}$ over half a decade, whereas the increase in $\mathrm{CO}_{2}$ in CMIP5 models is much slower and over the course of 50 years (Extended Data Table 2). As soil organic matter turns over slowly, the resulting $\beta_{\text {soil }}$ from experiments is lower than $\Delta$ Csoil from models, and the comparison not meaningful. We thus focus on the specific relationship $\beta_{\text {plant }}: \beta_{\text {soil }}$ in experiments vs. models. Here, we calculated the spatially explicit ratio of $\Delta \mathrm{Cveg}_{\mathrm{CMIP}}$ to

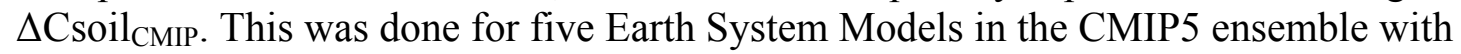
esmFixClim1 simulations (CanESM2; GFDL-ESM2M; HadGEM2-ES; IPSL-CM5A-LR; MPIESM-LR). Then, we calculate "expected" $\beta_{\text {soil }}$ from CMIP5 applying the same $\beta_{\text {plant }}$ used for experiments with the model-average $\Delta$ Cveg $_{\text {CMIP }}$ to $\Delta$ Csoil $_{\text {CMIP ratio: }}$

$$
\text { expected }\left(M g C h a^{-1}\right)=\beta \text { plant } \times \frac{\Delta C \text { soil }_{C M I P}}{\Delta C v e g_{C M I P}}
$$

With $\beta_{\text {plant }}$ as the effect of elevated $\mathrm{CO}_{2}$ on plant biomass derived from eCO experiments. We then computed the difference between the expected (modeled) and observed (upscaled) effects of elevated $\mathrm{CO}_{2}$ on $\beta_{\text {soil. }}$. As both expected and upscaled $\beta_{\text {soil }}$ use the same $\beta_{\text {plant }}$, this transformation allows us to directly tackle the consequences of the different $\beta_{\text {soil }} / \beta_{\text {plant }}$ ratios between experiments and models. We acknowledge, however, that the ratio is likely to change over time, so the comparison needs to be interpreted with caution. We found, however, that firstorder models also simulate a positive relationship between $\beta_{\text {soil }}$ and $\beta_{\text {plant }}$ when forced to simulate the same duration as experiments (Fig. 4a), suggesting that the sign of the $\beta_{\text {soil }}: \beta_{\text {plant }}$ relationship in CMIP5 models would not likely reverse if CMIP5 models would be forced to simulate a step increase in $\mathrm{CO}_{2}$ over 5 years as in experiments.

\section{Methods references}

41. Terrer, C. Report of Mutualistic Associations, Nutrients, and Carbon under eCO2 (ROMANCE) v1.0 dataset. (2020) doi:10.6084/m9.figshare.11704491.v7.

42. Dieleman, W. I. J. et al. Simple additive effects are rare: a quantitative review of plant biomass and soil process responses to combined manipulations of CO2 and temperature. Glob. Change Biol. 18, 2681-2693 (2012).

43. Borenstein, M., Hedges, L. V., Higgins, J. P. T. \& Rothstein, H. R. Multiple Outcomes or Time-Points within a Study. in 225-238 (John Wiley \&amp; Sons, Ltd, 2009).

44. Del Re, A. C. \& Hoyt, W. T. MAd: Meta-Analysis with Mean Differences. R Package Version 08-2 (2014).

45. Song, J. \& Wan, S. A global database of plant production and carbon exchange from global change manipulative experiments. (2020) doi:10.6084/m9.figshare.7442915.v9.

46. Viechtbauer, W. Conducting Meta-Analyses in R with the metafor Package. J. Stat. Softw. 36, (2010).

47. Osenberg, C. W., Sarnelle, O., Cooper, S. D. \& Holt, R. D. Resolving ecological questions through metaanalysis: goals, metrics, and models. Ecology 80, 1105-1117 (1999).

48. Rubin, D. B. \& Schenker, N. Multiple imputation in health are databases: An overview and some applications. Stat. Med. 10, 585-598 (1991).

49. Lajeunesse, M. J. Facilitating systematic reviews, data extraction and meta analysis with the metagear package for r. Methods Ecol. Evol. 7, 323-330 (2016).

50. Van Lissa, C. J. MetaForest: Exploring heterogeneity in meta-analysis using random forests. (2017) doi:10.31234/osf.io/myg6s.

51. Kuhn, M. Building Predictive Models in R Using the caret Package. J. Stat. Softw. 28, (2008).

52. Calcagno, V. \& de Mazancourt, C. glmulti: an R package for easy automated model selection with (generalized) linear models. J. Stat. Softw. 34, (2010).

53. van Groenigen, K. J. et al. Element interactions limit soil carbon storage. Proc. Natl. Acad. Sci. 103, 65716574 (2006). 
54. Wang, B. \& Qiu, Y. L. Phylogenetic distribution and evolution of mycorrhizas in land plants. Mycorrhiza 16, 299-363 (2006).

55. Maherali, H., Oberle, B., Stevens, P. F., Cornwell, W. K. \& McGlinn, D. J. Mutualism Persistence and Abandonment during the Evolution of the Mycorrhizal Symbiosis. Am. Nat. 188, E113-E125 (2016).

56. Terrer, C., Vicca, S., Hungate, B. A., Phillips, R. P. \& Prentice, I. C. Mycorrhizal association as a primary control of the CO fertilization effect. Science 353, 72-74 (2016).

57. Walker, A. et al. FACE-MDS Phase 2: Model Output. (2018) doi:10.15485/1480327.

58. Medlyn, B. E. et al. Using ecosystem experiments to improve vegetation models. Nat. Clim. Change 5, 528534 (2015).

59. Zaehle, S. et al. Evaluation of 11 terrestrial carbon-nitrogen cycle models against observations from two temperate Free Air CO2 Enrichment studies. New Phytol. 202, 803-822 (2014).

60. De Kauwe, M. G. et al. Where does the carbon go? A model-data intercomparison of vegetation carbon allocation and turnover processes at two temperate forest free-air CO 2 enrichment sites. New Phytol. 203, 883-899 (2014).

61. Walker, A. P. et al. Comprehensive ecosystem model data synthesis using multiple data sets at two temperate forest free air $\mathrm{CO} 2$ enrichment experiments: Model performance at ambient $\mathrm{CO} 2$ concentration. $J$. Geophys. Res. Biogeosciences 119, 937-964 (2014).

62. Walker, A. P. et al. Decadal biomass increment in early secondary succession woody ecosystems is increased by CO 2 enrichment. Nat. Commun. 10, 454 (2019).

63. Schlesinger, W. et al. The Duke Forest FACE Experiment: CO2 Enrichment of a Loblolly Pine Forest. in 197-212 (2006). doi:10.1007/3-540-31237-4_11.

64. Hungate, B. A. et al. Cumulative response of ecosystem carbon and nitrogen stocks to chronic $\mathrm{CO} 2$ exposure in a subtropical oak woodland. New Phytol. 200, 753-766 (2013).

65. Jordan, D. N. et al. Biotic, abiotic and performance aspects of the Nevada Desert Free-Air CO2 Enrichment (FACE) Facility. Glob. Change Biol. 5, 659-668 (1999).

66. Carrillo, Y., Dijkstra, F., LeCain, D., Blumenthal, D. \& Pendall, E. Elevated CO2 and warming cause interactive effects on soil carbon and shifts in carbon use by bacteria. Ecol. Lett. 21, 1639-1648 (2018).

67. Mueller, K. E. et al. Impacts of warming and elevated $\mathrm{CO} 2$ on a semi arid grassland are non additive, shift with precipitation, and reverse over time. Ecol. Lett. 19, 956-966 (2016).

68. Zak, D. R., Pregitzer, K. S., Kubiske, M. E. \& Burton, A. J. Forest productivity under elevated CO2 and O3: positive feedbacks to soil $\mathrm{N}$ cycling sustain decade long net primary productivity enhancement by $\mathrm{CO}$. Ecol. Lett. 14, 1220-1226 (2011).

69. Oleson, K. et al. Technical description of version 4.5 of the Community Land Model (CLM). (2013) doi:10.5065/D6RR1W7M.

70. Clark, D. B. et al. The Joint UK Land Environment Simulator (JULES), model description - Part 2: Carbon fluxes and vegetation dynamics. Geosci. Model Dev. 4, 701-722 (2011).

71. Krinner, G. et al. A dynamic global vegetation model for studies of the coupled atmosphere-biosphere system. Glob. Biogeochem. Cycles 19, (2005).

72. Haverd, V. et al. A new version of the CABLE land surface model (Subversion revision r4601) incorporating land use and land cover change, woody vegetation demography, and a novel optimisation-based approach to plant coordination of photosynthesis. Geosci. Model Dev. 11, 2995-3026 (2018).

73. Lawrence, D. M. et al. The Community Land Model Version 5: Description of New Features, Benchmarking, and Impact of Forcing Uncertainty. J. Adv. Model. Earth Syst. 11, 4245-4287 (2019).

74. Meiyappan, P., Jain, A. K. \& House, J. I. Increased influence of nitrogen limitation on CO2 emissions from future land use and land use change. Glob. Biogeochem. Cycles 29, 1524-1548 (2015).

75. Smith, B. et al. Implications of incorporating $\mathrm{N}$ cycling and $\mathrm{N}$ limitations on primary production in an individual-based dynamic vegetation model. Biogeosciences 11, 2027-2054 (2014).

76. Goll, D. S. et al. A representation of the phosphorus cycle for ORCHIDEE (revision 4520). Geosci. Model Dev. 10, 3745-3770 (2017).

77. Friedlingstein, P. et al. Global Carbon Budget 2019. Earth Syst. Sci. Data 11, 1783-1838 (2019).

78. Harris, I., Jones, P. D., Osborn, T. J. \& Lister, D. H. Updated high resolution grids of monthly climatic observations - the CRU TS3.10 Dataset. Int. J. Climatol. 34, 623-642 (2014).

79. Soudzilovskaia, N. A. et al. Global mycorrhizal plant distribution linked to terrestrial carbon stocks. Nat. Commun. 10, 1-10 (2019).

80. Hengl, T. et al. SoilGrids250m: Global gridded soil information based on machine learning. PLoS ONE 12, e0169748 (2017). 
81. Batjes, N. H. Harmonized soil property values for broad-scale modelling (WISE30sec) with estimates of global soil carbon stocks. Geoderma 269, 61-68 (2016).

82. Shangguan, W., Dai, Y., Duan, Q., Liu, B. \& Yuan, H. A global soil data set for earth system modeling. J. Adv. Model. Earth Syst. 6, 249-263 (2014).

\section{Code availability}

The $\mathrm{R}$ code used in the analysis presented in this paper is available in GitHub and can be accessed at https://github.com/cesarterrer/SoilC $\mathrm{CO}_{2}$

\section{Data availability}

All the empirical data that support the main findings of this study have been deposited in Figshare: (https://figshare.com/account/home\#/projects/74721) and GitHub (https://github.com/cesarterrer/SoilC $\mathrm{CO}_{2}$ ). FACE-MDS data can be accessed at https://www.osti.gov/dataexplorer/biblio/dataset/1480327. CMIP5 data can be accessed at https://esgf-index1.ceda.ac.uk/search/cmip5-ceda/. TRENDY data can be requested at http://dgvm.ceh.ac.uk/index.html.

\section{Acknowledgements}

We thank C. Körner, R. Norby, M. Schneider, K. Treseder, M. Hoosbeek and others for sharing data and advice. We thank the TRENDY, CMIP5 and FACE-MDS teams for the provision of the model simulations. C.T. was supported by a Lawrence Fellow award through Lawrence Livermore National Laboratory (LLNL). This work was performed under the auspices of the U.S. Department of Energy by LLNL under contract DE-AC52-07NA27344 and was supported by the LLNL-LDRD Program under Project No. 20-ERD-055. JBF contributed to this research the Jet Propulsion Laboratory, California Institute of Technology, under a contract with the National Aeronautics and Space Administration. BAH and KJVG contributed with support from the U.S. Department of Energy, Terrestrial Ecosystem Science Program DE-SC0010632. California Institute of Technology. Government sponsorship acknowledged. Funding provided in part by the NASA IDS program, and by the U.S. Department of Energy, Office of Science, Office of Biological and Environmental Research, Terrestrial Ecosystem Science Program under Award Numbers DE-SC0008317, DE-SC0016188 and the LLNL Soil SFA SCW1632. The FACE Model-Data Synthesis was supported by the U.S. Department of Energy, Office of Science Biological and Environmental Research program. Oak Ridge National Laboratory is operated by UT-Battelle, LLC, under contract DE-AC05-00OR22725 with the U.S. Department of Energy. Copyright 2020. All rights reserved. The BioCON experiment was funded by the Long-Term Ecological Research (LTER) grants DEB-0620652, DEB-1234162, and DEB1831944, Long-Term Research in Environmental Biology (LTREB) grants DEB-1242531 and DEB-1753859, Biological Integration Institutes grant NSF-DBI-2021898, Ecosystem Sciences grant DEB-1120064, and Biocomplexity grant DEB-0322057, and by the U.S. Department of Energy Programs for Ecosystem Research grant DE-FG02-96ER62291.

\section{Author contributions}

C.T and R.P.P. conceived the original idea. C.T. designed the paper, with R.B.J., B.A.H. and K.J.vG contributing to the development of the conceptual framework. J.R. and C.T. collected the biomass and soil carbon data from experiments. M.C. collected MAOM data. K.vS and S.V. collected litter data. C.T. ran the statistical analyses and upscaling. B.D.S ran the analysis with TRENDY models. B.N.S., C.T., and B.A.H. ran the comparison with the FACE MDS data. 
T.F.K, H.Z., and C.T. analyzed CMIP5 data. P.B.R., B.A.H., E.P., Y.C., R.D.E, R.B.J., and many others ran the experiments. C.T. and B.A.H. wrote the first draft, with input from all

\section{Competing interests}

The authors declare no competing interests.

\section{Additional information}

Supplementary Information is available for this paper

Correspondence and requests for materials should be addressed to C.T: terrer@stanford.edu

\section{Extended Data}

Extended Data Figure 1 | Relationship of the effects of $\mathrm{eCO}_{2}$ on aboveground biomass production with litter production (a) and soil carbon storage (b). Results for non-fertilized field $\mathrm{eCO}_{2}$ experiments ( $\mathrm{n}=10$, and $\mathrm{n}=35$, respectively). Dots represent individual experiments, with dot size in (b) proportional to the weights in the meta-regression.

Extended Data Figure 2 | Variable importance of 19 predictors of the effects of $\mathrm{CO}_{2}$ on soil carbon and biomass stocks. (a-b) Variable importance of the effect of $\mathrm{CO}_{2}$ on soil carbon stocks in (a) relative (\%) and (b) absolute terms $\left(\mathrm{g} \mathrm{m}^{-2}\right)$ across the full dataset $(\mathrm{n}=108)$. (c) Variable importance of the effect of $\mathrm{CO}_{2}$ on soil carbon stocks (\%) across the subset of $\mathrm{eCO}_{2}$ experiments in "intact" soils (n=73). (d) Variable importance of the effect of $\mathrm{CO}_{2}$ on plant aboveground biomass $(n=138)$. Variable importance in $(a, b, d)$ is quantified based on a metaforest model. Variable importance in (c) is quantified based on the sum of AICc weights, which allows for the quantification of the importance of interactions between predictors. As an initial step, moderators that consistently displayed negative variable importance (i.e., that showed a reduction in predictive performance) were automatically dropped.

Extended Data Figure 3 | Effects of elevated $\mathrm{CO}_{2}$ on soil carbon and plant biomass in the subset of nitrogen-fertilized $\mathbf{e C O}$ studies $(\mathbf{n}=\mathbf{3 5})$, expressed as a regression (a) and overall effects in meta-analysis (b). Dot sizes in (a) represent the individual studies and are drawn proportional to the weights in the model. The regression with the subset of non-fertilized studies is also shown here for comparison. Dots in (b) represent the effect sizes and 95\% confidence intervals from the meta-analysis.

Extended Data Figure $4 \mid$ Analysis of variables potentially explaining the observed effects of elevated $\mathrm{CO}_{2}$ on soil carbon. Effects of elevated $\mathrm{CO}_{2}$ on root biomass $(\mathrm{n}=45)$, fine-root production $(n=11)$, litter $\mathrm{C}: \mathrm{N}(\mathrm{n}=16)$ and background soil carbon stocks $(\mathrm{n}=38)$, between ecosystem types (grassland vs. forest) and nutrient-acquisition strategies (arbuscular mycorrhizae -AM- vs. ectomycorrhizae-ECM-). Boxplots show the median, the first to third quartile, the $1.5 \mathrm{x}$ interquartile ranges, and outliers.

Extended Data Figure 5 | Partial dependence plots of the six most important predictors of the effect of elevated $\mathrm{CO}_{2}$ on soil carbon stocks across 108 experiments. The figure shows the predicted $\mathrm{CO}_{2}$ effect (yi) in relative (a) and absolute terms (b) across each predictor and the most 
important interaction between predictors (right panels) in a random-forest meta-analysis. Error bands represent $95 \%$ confidence intervals. Partial regression plots give a graphical depiction of the marginal effect of a variable on the response and the shape and direction of the relationship. Little variation in yi across the values of a predictor generally reflects the low predictive power of the predictor for yi. However, important predictors may show little variation in yi when involved in interactions, so the right panels show the most important interaction in the model. More details about the different predictors in Extended Data Table 1. From a total of 19 here.

\section{Extended Data Figure 6 | Representativeness of the upscaling predictors of the effect of} elevated $\mathrm{CO}_{2}$ on soil carbon stocks. Histograms showing the distribution of both the predictors in the training dataset of $\mathrm{CO}_{2}$ experiments and the data used to upscale the global distribution of the effect. Predictions exclude regions between -15 to 15 and from 60 to 90 degrees latitude due to the lack of experiments.

Extended Data Figure 7 | Relationship between the effects of $\mathrm{CO}_{2}$ on aboveground biomass and soil carbon across individual models from three model ensembles. (a) FACE Model Data Synthesis Phase 2. Individual model results are represented by colored symbols and lines. Each symbol represents one site; lines represent model-specific linear regressions. To ease interpretation of the results and the comparison with Fig. 4 axis limits are set. Dashed line and error band represent the linear regression line and standard error across all experiment-by-model results. (b) TRENDY v7 models. (c) CMIP5 models.

Extended Data Figure 8 | Difference between expected $\mathrm{CO}_{2}$ effects on soil carbon stocks based on TRENDY models and upscaled based on experiments. Expected values result from the relationship between $\beta_{\text {soil }}$ and $\beta_{\text {plant }}$ coded in models. Positive values (red color) indicate an overestimation by models; negative values (blue color) indicate an underestimation by models.

Extended Data Table 1 | List of predictors used to examine and upscale the effects of elevated $\mathrm{CO}_{2}$ on soil carbon.

Extended Data Table 2 | Synthetic description of the basic characteristics of three model ensembles in terms of their treatment of $\mathrm{CO}_{2}$ effects. 


\section{Ecosystem type}

Agricultural (27) Grassland (24) Shrubland (6) Tree Stand (50)

Nitrogen fertilization

Yes

No
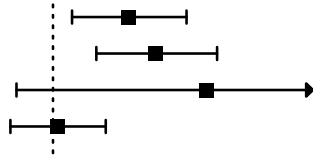

Soil C stocks ( $\mathrm{g} \mathrm{m}^{-2}$ ) $[193,1512)(36)$ $[1512,2927)(36)$ $[2927,8021](36)$

Experiment type Chamber FACE OTC

Disturbance Disturbed Intact

Nutrient strategy AM ECM AM-ER $\mathrm{N}$-fixer (46) (10)

Overall effect
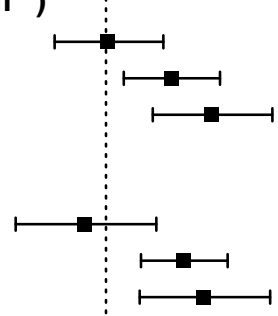

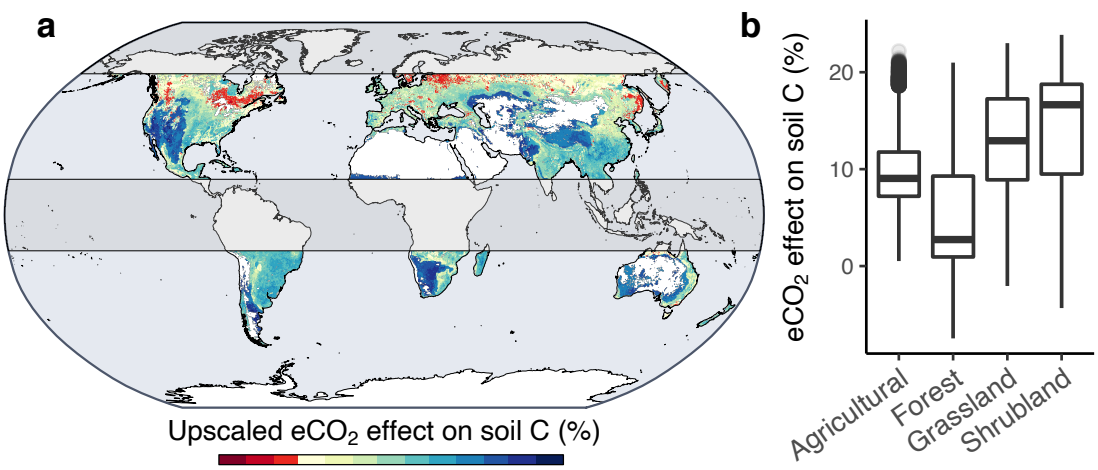

$\begin{array}{lllllll}-5 & 0 & 5 & 10 & 15 & 20 & 25\end{array}$

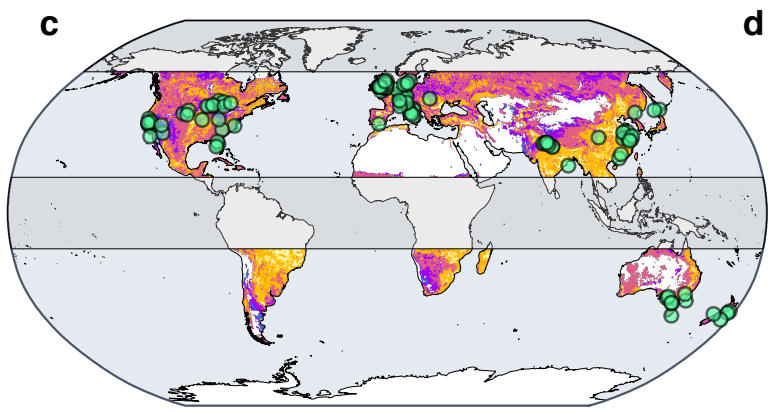

Uncertainty in soil C estimate (\%)

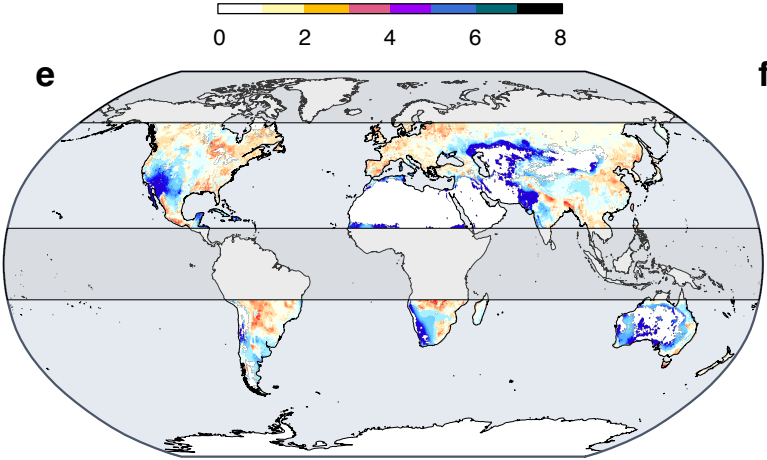

(Expected - Upscaled) change in soil C (\%)
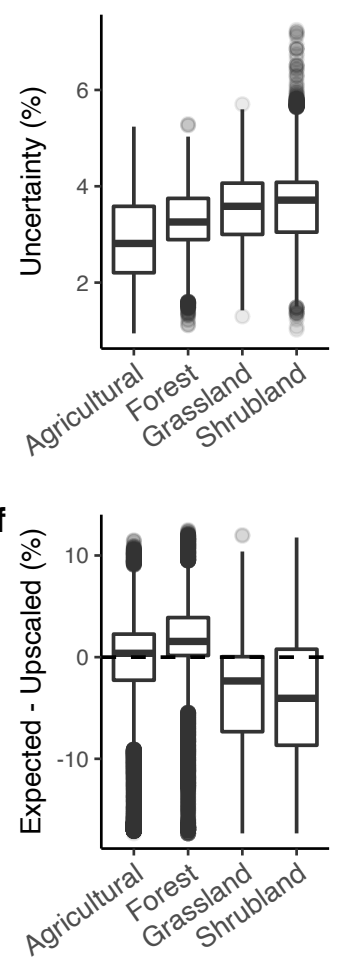

$\begin{array}{lllllll}-15 & -10 & -5 & 0 & 5 & 10 & 15\end{array}$ 
